\title{
Biological Clock Supposed to be in the Optic Ganglion of the Prawn
}

\author{
Kaworu Nakamura* \\ (Accepted August 26, 1986)
}

\begin{abstract}
The diurnal rhythm of feeding was examined by the removal, covering, local cauterization and local cutting of the eyestalk for clarification on the portion of the optic ganglion related to its mechanism in the prawn $\boldsymbol{P}$. japonicus.

From the results of the removal and covering experiments, it was confirmed that the eyestalk participated endogeneously in the maintenance of the prawn's diurnal rhythm. The local operations of cauterization and cutting indicated the medulla terminalis of the optic ganglion as the essential site of the mechanism, because of the disappearance of the diurnal rhythm after each treatment.

Further, histological investigation was tried to identify the medullary cells as components of the mechanism for the prawns reared under two different conditions of continuous light. After rearing for 10 and 30 days, the cells revealed a significant change in the diametric ratio of the nucleus to its cytoplasm (nucleo-cytoplasm ratio) between the day-time and night-time samplings, notwithstanding the rearing period and light condition.

The medulla terminalis was supposed to be the oscillator, or its component, of the biological clock in the prawn due to its stable rhythmicity with the cellular activity reflected from the nucleocytoplasm ratio.
\end{abstract}

The eyestalk in Crustacea is physiologically an important site, possessing the $x$ organ-sinus gland complex which is involved in the endocrinological control for molting, ovarian development, chromatophore behavior and hemolymph level of sugars, as well as being a component of the sensory receptive mechanism. ${ }^{1-3}$ )

Further, it has been proven that the eyestalk participates in the diurnal rhythm of locomotion in crayfishes and crabs. ${ }^{4-9)}$ In the crayfish Orconectes pellucides, blinded individuals which had intact eyestalks showed the diurnal rhythm of locomotion. ${ }^{10)}$ This manifestation of the eyestalk has been considered to be controlled by the endocrinological ${ }^{9,11-13)}$ or nervous system. ${ }^{\text {s) }}$ However, until now, its mechanism has not been proven. ${ }^{14}$

For the medulla terminalis in the eyestalk, some suggestions concerning its role as the oscillator or the biological clock have been reported. Diurnal rhythm of feeding disappeared after removal of the medulla terminalis in the spiny lobster Panulirus argus. ${ }^{15)}$ Many patterns of behaviors were disturbed after the medulla terminalis received the damage in the crab Podophthalmus vigil and spiny lobster Panulirus japonicus. ${ }^{18)}$

In this report, experiments were firstly conducted to confirm the participation of the eyestalk in the diurnal rhythm of feeding in the prawn Penaeus japonicus. Localization of the controlling site as the oscillator of the biological clock was also investigated.

\section{Material and Methods}

The prawn Penaeus japonicus weighing about $10 \mathrm{~g}$ were used in the present experiments.

The right eyestalk immersed previously in $70 \%$ ethanol was dissected to expose the dorsal area for the anatomical observation of the internal construction. Its description was used as a reference map for the local operations executed later. For the histological observation, both of the eyestalks fixed in Bouin solution were dehydrated with ethanol series, then embedded in paraffin. After sectioning, they were stained with PAS-hematoxylin.

Rearing experiments for the confirmation of the role of the eyestalk in the maintenance of the diurnal rhythm of feeding were performed after its bilateral removal by compression with hot tweezers or its covering with aluminium-foil cap. Next rearing experiments were done after eyestalkoperation by local cauterization with a hot needle or by local cutting with a razor. At the end of

\footnotetext{
* Faculty of Fisheries, Kagoshima University, Kagoshima, 890, Japan (中村 藏：鷹児島大学水産学部).
} 
the experiment, eyestalks were subjected to histological observation for the identification of the essential site for the mechanism. During each experiment, enough amount of pellets were given quantitatively, depending upon each individual's consumption. The amount of food consumed was recorded every day, and presented as the feeding pattern. Temperature was $23.5-27.0^{\circ} \mathrm{C}$.

Third experiment of two different periods, 10 and 30 days, was undertaken for intact prawns under $24 \mathrm{~h}$ of continuous light $(10-40 \mathrm{~lx})$ or continuous dark. Each group contained 14 individuals. The light group was reared individually in $20 l$ acrylic containers, and all the individuals of the dark group was reared in a $200 l$ polyurethane container. As for the illumination of the light group, paired fluorescent lamps of $40 \mathrm{~W}$ were suspended about $1 \mathrm{~m}$ above the containers, and covered with blue polyethylene sheets to reduce the light intensity. For the dark group, its container was always covered with a black vinyl sheet except during sampling, water exchange and cleaning of sand, which were done only if necessary. During these treatments, external light of about $5 \mathrm{~lx}$ at the water surface entered into the container. Pellets were given around 17:00-20:00. After rearings for 10 and 30 days, the eyestalk and brain of each individual were extirpated and put into the fixative at the sampling time of 9:00-13:00 or 20:00-23:30. Then, they were subjected to the histological examination of the diurnal rhythm of cellular activity. For the eyestalk, 20-30 $\mu \mathrm{m}$ cells distributed on the medulla terminalis of the optic ganglion were examined. And for the brain, two paired cells of $35-45 \mu \mathrm{m}$, situated locally at the intercerebral part of the ganglion, were chosen for the inspection. Estimation of the diurnal rhythm of each cell was done by comparing the diametric ratios between the day-time and night-time. The diametric ratio is the ratio of a nuclear diameter to its cytoplasmic one (nucleo-cytoplasm ratio) and serves as an index of the cellular activity. The measurement was repeated 10-20 times using a micrometer for about 10 medullary cells or all of the intercerebral cell, and each average was used for the individual value. Temperature during rearings ranged from $23.0^{\circ} \mathrm{C}$ to $30.0^{\circ} \mathrm{C}$.

\section{Results and Discussion}

\section{Structure of Eyestalk and Brain}

Internal construction of the eyestalk is shown

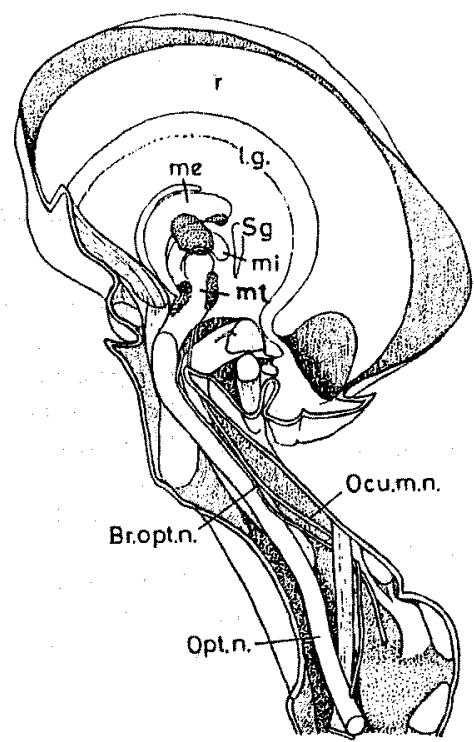

Fig. 1. Dorsal view of the optic ganglion and other components of the right eyestalk. Dotted area on the ganglion shows populations of cells.

Br. opt. n., branch of the optic nerve; l.g., lamina ganglionaris; me, medulla externa; mi, medulla interna; mt, medulla terminalis; Ocu. m.n., oculomotor nerve; Opt. n., optic nerve; r, retina layer; $\mathrm{Sg}$, sinus gland.

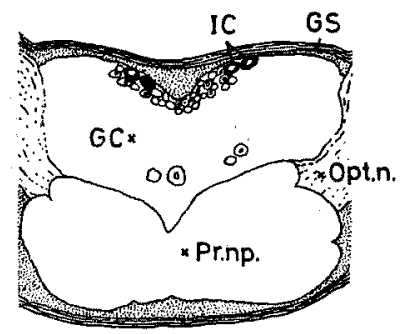

Fig. 2. Diagram of the anterior part of the brain, sectioned transversally. Many cells in the cell group are omitted.

GC, group of cells; GS, ganglion sheath; IC, intercerebral cell; Opt. n., optic nerve; Pr. np., protocerebral neuropile.

in Fig. 1. At the stalk part, optic and oculomotor nerves are distributed with muscular components. The swollen tip of the optic nerve extending into the eye-cup is named medulla terminalis, and is distally linked with the medulla internal and medulla external, both like a mushroom cap. The lamina ganglionaris and retina layer are arranged at the periphery of the medullae. The medulla 


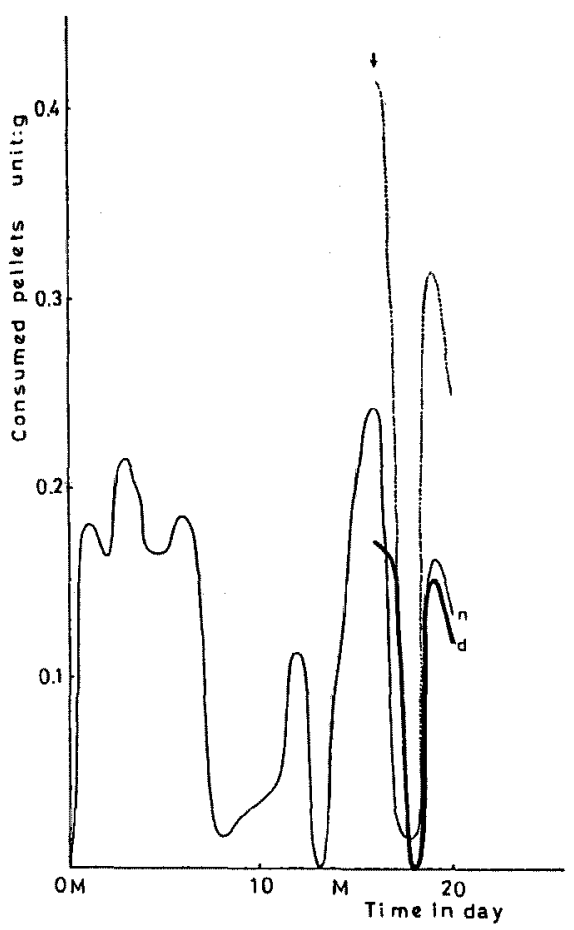

Fig. 3. Changes in feeding pattern of the prawn following eyestalk-ablation. The arrow indicates the day of ablation. The dotted line shows a daily sum of the day (d) and night (n) time consumptions. The $\mathbf{M}$ on the abscissa means the molting day.

external and medulla terminalis possess relatively large populations of nerve cells on the limited area of their superficial layer.

Detailed structure of the brain has been presented previously. ${ }^{17}$ ) In this examination, only the nerve cell which has some relation to the mechanism of the biological clock is referred. As shown in Fig. 2, the intercerebral cell is situated at the intercerebral part of the protocerebral neuropile in the antero-dorsal portion of the brain.

Experiment 1. Effects of Eyestalk-Ablation and Eyestalk-Covering on Feeding Activity

A typical feeding pattern of the eyestalk-ablated prawn is shown in Fig. 3. Such a pattern was obtained for all the 10 individuals of treated prawns. Its diurnal rhythm disappeared just after the operation, and the amount of pellets diurnally consumed increased about two times due to the day-time ingestion in addition to feeding at night. As for four eyestalk-covered prawns, the diurnal rhythm of feeding has not been disturbed.

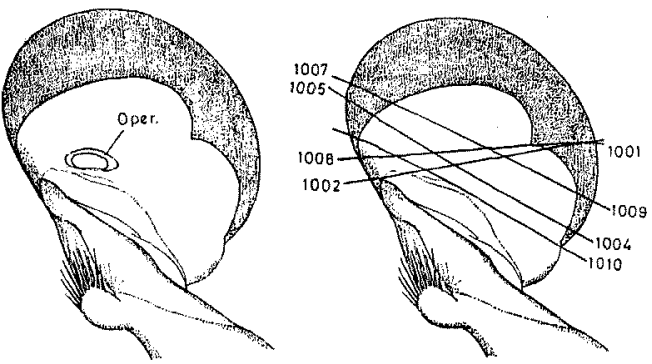

Fig. 4. Operated site of the dorsal eye-cup of the right eyestalk subjected to local cauterization (left figure).

Cutting levels of the right eyestalk subjected to the local cutting operation. The number indicates the individual No., treated in this experiment (right figure).

Table 1. Effects of the local cutting of the eyestalk on the diurnal rhythm of feeding behavior

\begin{tabular}{cccc}
\hline $\begin{array}{c}\text { Indiv. } \\
\text { No. }\end{array}$ & $\begin{array}{c}\text { Diurnal } \\
\text { rhythm*1 }\end{array}$ & $\begin{array}{c}\text { Histological } \\
\text { M. externa }\end{array}$ & $\begin{array}{c}\text { degeneration*2 } \\
\text { M. terminalis }\end{array}$ \\
\hline 1001 & + & + & - \\
1002 & - & + & + \\
1004 & + & + & - \\
1005 & + & + & - \\
1007 & + & - & - \\
1008 & + & - & - \\
1009 & + & - & - \\
1010 & - & + & + \\
\hline *1 &,+ Persisting; -, Losing. \\
*2 Including neuropile and cells; +, Positive; -, Negative.
\end{tabular}

Therefore, it is confirmed that the eyestalk of the prawn $P$. japonicus participates in the control of the diurnal rhythm of feeding, as in the spiny lobsters and crabs. ${ }^{15,10}$ ?

\section{Experiment 2. Effects of Eye-Cauterization and Eye-Cutting on Feeding Activity}

The cauterized site of the eyestalk is indicated in Fig. 4. Feeding patterns of the eight operated prawns were similar to those of the eyestalkablated ones. But detailed observation to identify the position of the ganglion related to the biological clock was difficult because unexpected spread of histological degeneration on the optic ganglion.

Results from the local cutting of the eyestalk have answered this indeterminacy. The cutting level on the eye-cup is shown in Fig. 4. Each cutting line is anyhow set on one of the medullae. As shown in Table 1, the diurnal rhythm of feeding was maintained if the cutting level did not 
Table 2. Nucleo-cytoplasm ratios of $20-30 \mu \mathrm{m}$ cells of the medulla terminalis under continuous light (LL) and continuous dark (DD) conditions

\begin{tabular}{|c|c|c|c|c|}
\hline \multirow{3}{*}{ Trial } & \multicolumn{4}{|c|}{ Nucleo-cytoplasm ratio*1 on 10 th day } \\
\hline & \multicolumn{2}{|c|}{ LL } & \multicolumn{2}{|c|}{$\mathrm{DD}$} \\
\hline & $9: 00-11: 30$ & $21: 00-23: 10$ & $9: 00-11: 40$ & $20: 00-22: 30$ \\
\hline 1 & $47.0 * 2$ & 44.5 & 46.0 & 45.2 \\
\hline 2 & 46.8 & 43.0 & 46.7 & 43.0 \\
\hline 3 & 46.0 & 44.7 & 46.1 & 45.0 \\
\hline 4 & 47.0 & 44.1 & 46.9 & 44.1 \\
\hline 5 & 45.5 & 45.8 & 45.8 & 44.4 \\
\hline 6 & 44.5 & 44.9 & 45.4 & 44.7 \\
\hline 7 & 45.0 & 45.3 & - & 45.2 \\
\hline \multirow[t]{2}{*}{ av. $\pm S D$} & $46.0 \pm 0.94$ & $44.6 \pm 0.83$ & $46.2 \pm 0.51$ & $44.5 \pm 0.73$ \\
\hline & \multirow{2}{*}{\multicolumn{4}{|c|}{ Nucleo-cytoplasm ratio on 30 th day }} \\
\hline \multirow[t]{2}{*}{ Trial } & & & & \\
\hline & $9: 00-12: 30$ & $20: 30-23: 00$ & $9: 00-13: 00$ & $20: 00-23: 30$ \\
\hline 1 & 44.5 & 45.0 & 45.0 & 43.8 \\
\hline 2 & 45.6 & 44.6 & 46.7 & 44.0 \\
\hline 3 & 45.4 & 43.8 & 45.7 & 43.4 \\
\hline 4 & 44.9 & 44.2 & 46.0 & 45.1 \\
\hline 5 & 45.4 & 44.1 & 46.4 & 43.6 \\
\hline 6 & 45.6 & 44.8 & 46.1 & 42.9 \\
\hline 7 & 45.5 & 44.9 & 45.6 & 43.0 \\
\hline av. \pm SD & $45.3 \pm 0.39$ & $44.5 \pm 0.42$ & $45.9 \pm 0.52$ & $43.7 \pm 0.69$ \\
\hline
\end{tabular}

*1 Nuclear diameter $\times 100 /$ cytoplasmic diameter.

*2 Each value corresponds to the average of one prawn.

Table 3. Nucleo-cytoplasm ratios of the intercerebral cell of the brain under continuous light (LL) and continuous dark (DD) conditions

\begin{tabular}{|c|c|c|c|c|}
\hline \multirow{3}{*}{ Trial } & \multicolumn{4}{|c|}{ Nucleo-cytoplasm ratio*1 on 10 th day } \\
\hline & \multicolumn{2}{|c|}{ LL } & \multicolumn{2}{|c|}{ DD } \\
\hline & $9: 00-11: 30$ & $21: 00-23: 10$ & $9: 00-11: 40$ & $20: 00-22: 30$ \\
\hline 1 & $44.0 * 2$ & 47.4 & 45.4 & 40.4 \\
\hline 2 & 43.9 & 46.1 & 45.3 & 44.4 \\
\hline 3 & 43.1 & 46.4 & 46.8 & 45.3 \\
\hline 4 & 44.8 & 46.8 & 44.0 & 45.5 \\
\hline 5 & 46.7 & 45.3 & 44.9 & 47.2 \\
\hline 6 & 45.1 & 46.0 & 45.4 & 44.6 \\
\hline 7 & 45.7 & 45.1 & 45.2 & 47.5 \\
\hline \multirow[t]{2}{*}{ av. $\pm \mathrm{SD}$} & $44.8 \pm 1.12$ & $46.2 \pm 0.75$ & $45.3 \pm 0.77$ & $45.0 \pm 2.17$ \\
\hline & \multicolumn{4}{|c|}{ Nucleo-cytoplasm ratio on 30 th day } \\
\hline \multirow[t]{2}{*}{ Trial } & \multicolumn{2}{|c|}{ LL } & \multicolumn{2}{|c|}{ DD } \\
\hline & $9: 00-12: 30$ & $20: 00-23: 30$ & $9: 00-13: 00$ & $20: 00-23: 30$ \\
\hline 1 & 44.7 & 44.7 & 44.8 & 44.4 \\
\hline 2 & 45.5 & 46.0 & 41.8 & 47.6 \\
\hline 3 & 44.3 & 46.0 & 43.8 & 43.3 \\
\hline 4 & 44.0 & 44.0 & 43.2 & 45.3 \\
\hline 5 & 45.6 & 44.5 & 44.5 & 47.0 \\
\hline 6 & 42.4 & 47.3 & 45.0 & 48.4 \\
\hline 7 & 44.1 & 48.0 & 42.4 & 46.8 \\
\hline av. $\pm S D$ & $44.4 \pm 1.00$ & $45.8 \pm 1.38$ & $43.6 \pm 1.14$ & $46.1 \pm 1.70$ \\
\hline
\end{tabular}

*1 Nuclear diameter $\times 100 /$ cy toplasmic diameter.

*2 Each value corresponds to the average of one prawn. 
reach to the medulla terminalis.

The medulla terminalis is, therefore, considered to be an essential site for the maintenance of the diurnal rhythm of feeding in the prawn $P$. japonicus. For the biological clock of the cockroach, there have been two supposed sites of the oscillator..$^{18-21}$ These are the optic lobe and intercerebral part in the brain. These assumptions are discussed for the prawn in the 3 rd experiments.

Experiment 3. Effects of Continuous Light and Dark Conditions on the Nucleo-Cytoplasm Ratio of the Medullary and Intercerebral Cells

The nucleo-cytoplasm ratio for the cells of the medulla terminalis after 10 and 30 days under continuous light and dark conditions is shown in Table 2. After rearings for 10 and 30 days, the mean values of the prawns sampled in the daytime are significantly higher $(p<0.01, t$-test) than those of the night-time sampling, notwithstanding the condition of light. Furthermore, the diurnal rhythm in the feeding behavior was maintained in the individuals under both light conditions.

These results suggest that the cells of the medulla terminalis possess an extremely stable pattern of the diurnal activity unrelated to the external photoperiod. Short-time entrances of faint light during rearing managements under continuous dark condition do not seem to have influenced the cellular activity because of insignificant differences in the day-time value when compared to that of the light condition.

The nucleo-cytoplasm ratio of the intercerebral cell is shown in Table 3 . There is no significant difference between the mean values of the prawns sampled at night and day-time.

As a result, the intercerebral cell can not be said to be the oscillator or its component of the biological clock, differing from the cells of the medulla terminalis in the eystalk. For the medulla terminalis, it is supposed to be an intrinsic site of the biological clock for the prawn $P$. japonicus.

\section{References}

1) L.M. Passano: in "The Physiology of Crustacea" (ed. by T. H. Waterman), Vol. 1, Academic Press, New York and London, 1960, pp. 473-536.

2) K. G. Adiyodi and R. G. Adiyodi: Biol. Rev., 45, 121-165 (1970).

3) I. M. Cooke and R. E. Sullivan: in "The Biology of Crustacea" (ed. by D. E. Bliss), Vol. 3, Academic Press, New York and London, 1982, pp. 205-290.

4) H. Kalmus: Z. vergl. Physiol,, 25, 784-797 (1938).

5) H. Kalmus: $Z$. vergl. Physiol., 25, 798-802 (1938).

6) W. Schalleck: J. Exp. Zool., 91, 155-166 (1942).

7) D. E. Bliss: Biol. Bull., 104, 275-296 (1953a).

8) D. E. Bliss: Anat. Rec., 117, 599 (1953b).

9) E. Naylor and B. G. Williams: J. Exp. Biol., 49, 107-116 (1968).

10) T. C. Jegla and T. L. Poulson: J. Exp. Zool., 168, 273-282 (1968).

11) T. W. Roberts: Anat. Rec., suppl., 81, 46-47 (1941).

12) D. E. Bliss: in "Neurosecretion" (ed. by $\boldsymbol{H}$. Heller and R. B. Clark), Academic Press, New York and London, 1962, pp. 391-410.

13) B. L. Powell: Gen. Comp. Endocrinol., 5, 705 (1965).

14) H. Aréchiga: Federation Proc., 36, 2036-2041 (1977).

15) D. M. Maynard and A. Sallee: Z. vergl. Physiol., 66, 123-140 (1970).

16) B. A. Hazlett: $\quad Z$. vergl, Physiol, 71, 1-13 (1971).

17) K. Nakamura: Mem. Fac. Fish. Kagoshima Univ., 23, 173-184 (1974) (in Japanese).

18) S. K. Robert: J. Cell. Physiol., 67, 473-486 (1966).

19) J. Nishiitsutsuji-Uwo and C. S. Pittendrigh: $Z$. vergl. Physiol., 58, 1-13 (1968).

20) J. Nishiitsutsuji-Uwo and C.S. Pittendrigh: $Z$. vergl. Physiol, 58, 14-46 (1968).

21) J. Brady: Nature, 223, 781-784 (1969). 